\title{
Cisplatin and Vinorelbine -Mediated Electrochemotherapeutic Approach Against Multidrug Resistant Small Cell Lung Cancer (H69AR) In Vitro
}

\author{
MAŁGORZATA DRĄG-ZALESIŃSKA ${ }^{1}$, JOLANTA SACZKO ${ }^{2}$, ANNA CHOROMAŃSKA ${ }^{3}$, \\ ANNA SZEWCZYK ${ }^{2}$, NINA REMBIAŁKOWSKA ${ }^{2}$, JULITA KULBACKA ${ }^{2}$ and ADAM RZECHONEK ${ }^{4}$ \\ ${ }^{1}$ Department of Human Morphology and Embryology, Wroclaw Medical University, Wroclaw, Poland; \\ ${ }^{2}$ Department of Molecular and Cellular Biology, Wroclaw Medical University, Wroclaw, Poland; \\ ${ }^{3}$ Department of Medical Biochemistry, Wroclaw Medical University, Wroclaw, Poland; \\ ${ }^{4}$ Department of Thoracic Surgery, Wroclaw Medical University, Wroclaw, Poland
}

\begin{abstract}
Background/Aim: Small cell lung cancer (SCLC) originates from neuroendocrine branchial cells (15-20\%). It is regarded as distinct from other lung cancers due to its biological and clinical features. In most cases of SCLC, surgery or radiotherapy alone is not an effective cure. The aim of our study was to examine the cytotoxic effects of chemotherapy supported by electroporation (EP) on a resistant SCLC model, in vitro. Material and Methods: The multidrug resistant small lung cell line H69AR was used to evaluate the cytotoxic effects of cisplatin (CPPD) and vinorelbine (Navirel $\left.{ }^{\circledR} ; N A V\right)$ at lower doses when used with $E P$. Cells were treated with different concentrations of CPPD and NAV, alone or in combination with the following EP parameters: $400-1200 \mathrm{~V} / \mathrm{cm}, 8$ pulses of $100 \mu \mathrm{s}$ duration, at $1 \mathrm{~Hz}$. The cell viability was estimated by MTT assay after 24 and $48 \mathrm{~h}$. Apoptotic cells were detected by neutral comet assay and immunofluorescence assay with PARP-6. Results: CPPD and NAV alone showed a dose-dependent effect on cell viability. Cytostatic drugs combined with EP revealed increased anticancer activity. Lower doses of CPPD or NAV delivered by EP were as effective as higher doses of these drugs without EP. The electrochemotherapeutic protocols increased the number of apoptotic cells and increased immunoreactivity of PARP-6. Our results indicated higher sensitivity of H69AR cells to NAV supported by EP. Conclusion: In SCLC cells, an increased anticancer activity was potentiated by exposure of cells to high intensity electric
\end{abstract}

Correspondence to: Julita Kulbacka, Department of Molecular and Cellular Biology, Wroclaw Medical University, Wroclaw, Poland. Tel.: +48 7840692, Fax: +48 717840200, e-mail: julita.kulbacka@ umed.wroc.pl

Key Words: Small cell lung cancer, electrochemotherapy, cisplatin, vinorelbine. pulses and low drug doses. It is suggested that this method could be effectively applied in the treatment of lung cancer.

Small cell lung cancer (SCLC) is an aggressive disease generated, inter alia, from neuroendocrine branchial cells (15-20\%) (1-3). The original staging system for SCLC was established in 1968 by the Veterans Administration Lung Cancer Study Group; SCLC was divided into two clinical subgroups: limited disease (LD-SCLC) with pure histology and extensive disease (ED-SCLC) with pure and combined histology $(4,5)$. Moreover, SCLC is considered as different from other lung cancers due to its biological and clinical features. In comparison to non-small cell lung cancer (NSCLC), the SCLC demonstrates rapid and aggressive growth, early range to distant tissue, and the highest malignancy $(1,5,6)$.

In SCLC only $30 \%$ of cancers have a chance for complete remission $(7,8)$. Currently, surgical removal of lesions or radio- and chemotherapy plays an important role in systemic treatment of NSCLC. In most cases of SCLC, the surgery or radiotherapy alone is not an effective method (5-9). SCLC is a systemic disease where chemotherapy (CT) is less effective than surgery, because of association with the early formation of metastases via the blood system. The combined CT or CT and radiotherapy implicates better results in SCLC treatment, but survival median increases up to only two years. In comparison to single drug therapy, combined treatment gives a higher percentage of positive response to drugs and increase patients' survival. Currently, the 5-years survival occurs less than $2 \%$ (7-9). The high rate of the recurrence and the failure of chemotherapy is caused due to primary or secondary drug resistance phenomena in most of SCLC cases (1). The multidrug resistance (MDR) phenotype has been demonstrated in diverse types of cancer cells. It is commonly known, that the mechanism of MDR is a complex process and can be caused by single or multiple factors, however, its mechanism 
is not fully elucidated (10). Currently applied therapies against SCLC exhibit low efficiency and poor patient survival. This implicates the need for an improvement of drug bioavailability and delivery $(8,9)$. One possible option for improving drug delivery is electroporation (EP) technique, which reversibly acts on cell membrane to make it more permeable for drug molecules. EP combined with standard chemotherapy, named electrochemotherapy (ECT), is one of the recently used techniques against various types of cancer $(11,12)$. EP enables or simplifies the transport of various chemotherapeutics, whose diffusion is impeded through the cell membrane barrier due to their physicochemical properties or molecules size (11). The ongoing thoroughgoing studies brought about the development of a standard ESOPE protocol (8 pulses, 1000 $\mathrm{V} / \mathrm{cm} 100 \mu \mathrm{s})(13)$. Moreover, the beneficial effect of ECT in increasing drug efficiency in cancer cells and decreasing the applied dose of chemotherapeutic has been shown in multiple in vitro and in vivo models (13-21). Some researchers indicate also thermal ablation techniques including irreversible electroporation (IRE) as appropriate methods for the treatment of lung, liver, kidney and bone tumors (22).

In the present study we examined whether standard chemotherapy supported by EP may have increased cytotoxic effects on SCLC in vitro model with multidrug resistance (MDR). Therefore, human SCLC cell line H69AR with MDR was selected and treated with ECT, using low doses of the cytostatic drugs cisplatin and vinorelbine. The understanding of EP phenomena in combination with cytostatic drugs may be helpful in addressing chemoresistance and looking for alternative strategies to overcome chemoresistance in SCLC patients.

\section{Materials and Methods}

Cell culture. The small lung cancer cell line H69AR (ATCC, LGC Standards, Middlesex, UK) was used in this study. H69AR cells are defined as multidrug resistant type of cancer cells, derived from the 55-year-old Caucasian man. Cells were grown in polystyrene flasks with $25 \mathrm{~cm}^{2}$ cell culture surface (Eppendorf, Hamburg, Germany) as a monolayer in RPMI-1640 Medium (Gibco, Warsaw, Poland) supplemented with $20 \%$ fetal bovine serum (FBS; Sigma-Aldrich, Poznan, Poland) and $50 \mu \mathrm{g} / \mathrm{ml}$ streptomycin (Sigma-Aldrich). Cells were incubated at $37^{\circ} \mathrm{C}$ in $5 \% \mathrm{CO}_{2}$. Before every experiment, cells were washed by DPBS (Sigma-Aldrich) and trypsinized using $0.25 \%$ trypsin with $0.02 \%$ EDTA (Sigma-Aldrich).

Viability assay. The viability of cells was determined by MTT assay (Sigma-Aldrich, Poland, Poznan). The cells were seeded into 96-well microculture plates $\left(1 \times 10^{4}\right.$ cells/well $)$ and grown overnight. Then, cells were incubated with different concentrations of two cytostatic drugs, cisplatin (CPPD) and vinorelbine (Navirel ${ }^{\circledR}$; NAV) for 24 and $48 \mathrm{~h}$. After incubation, MTT assay was performed according to the manufacture's protocol. The absorbance was measured using a multiwell spectrophotometer at $570 \mathrm{~nm}$ (EnSpire Multiplate reader, Perkin Elmer, Boston, USA). Cell viability was expressed as a percentage of viable cells in relative to untreated control cells.
Electroporation protocol. Electroporation procedure of cells was performed using the ECM 830 device (BTX Harvard Apparatus, Syngen Biotech, Wroclaw, Poland), generating square wave pulses in the range of 5-3000 V/cm, 10-999 $\mu$ s long, in the series of 1-99. The cells were suspended in the EP buffer ( $\mathrm{pH} 7.4 ; 10 \mathrm{mM}$ phosphate, 1 $\mathrm{mM} \mathrm{MgCl} 2,250 \mathrm{mM}$ sucrose) with low electrical conductivity $(0.14$ $\mathrm{S} / \mathrm{m}$ ) and placed in cuvettes with two aluminum parallel electrodes with a gap of $4 \mathrm{~mm}$. Electroporation experiment was performed using the following pulsing parameters: $400,800,1000$ or $1200 \mathrm{~V} / \mathrm{cm} ; 8$ pulses of $100 \mu$ s duration and $1 \mathrm{~Hz}$ interval between pulses.

Electrochemotherapy in vitro. The effect of the combined EP with chemotherapy (CPPD and NAV) was examined in H69AR small cell lung cancer cells, in comparison to the control untreated cells. Sublethal drug concentrations and EP conditions were selected according cytotoxicity studies as follows: $1 \mu \mathrm{l} / \mathrm{ml}$ for CPPD and $0.1 \mu \mathrm{l} / \mathrm{ml}$ for NAV. CPPD and NAV were freshly prepared before each experiment by dissolving in EP buffer. Then the drugs were added to the cell suspensions in cuvettes and exposed to electric pulses. After $10 \mathrm{~min}$ of resealing time in $37^{\circ} \mathrm{C}$, cells were resuspended in the culture medium and used for cell viability studies (after 24 and $72 \mathrm{~h}$ ), apoptosis evaluation or immunoreactivity studies. The schematic representation of the experiment is presented in the Figure 1.

Apoptosis evaluation by neutral comet assay (NCA). Detection of DNA fragmentation associated with apoptosis, neutral comet assay method described by Collins was used (23). The cells $\left(1 \times 10^{5} / \mathrm{ml}\right)$ were mixed with low temperature melting agarose at a ratio of 1:10 $(\mathrm{v} / \mathrm{v})$ and spread on a slide glass. Slides were submerged in precooled lysis buffer (2.5 M NaCl, $100 \mathrm{mM}$ EDTA, pH 10, $10 \mathrm{mM}$ Tris base and $1 \%$ Triton $\mathrm{X}-100)$ at $4^{\circ} \mathrm{C}$ for $60 \mathrm{~min}$. After lysis and rinsing, slides were equilibrated in TBE solution (40 mM Tris/boric acid, $2 \mathrm{mM}$ EDTA, $\mathrm{pH} 8.3$ ), electrophoresed at $1.0 \mathrm{~V} / \mathrm{cm}^{2}$ for 20 $\mathrm{min}$, and then silver staining was performed. For scoring the comet pattern 100-200 nuclei were counted from each slide. The ranking of apoptotic comets by the method developed by Collins was performed (23).

Immunofluorescent evaluation of PARP-6. The confocal microscope was used to evaluate PARP-6 (poly(ADP-ribose) polymerase family member, a marker of apoptosis promotion and inhibition of cell proliferation (24), by immunofluorescent studies. H69AR cells, after treatment with EP alone or combined with cytostatic drugs, were resuspended on microscopic cover slides in $35 \mathrm{~mm}$ Petri dishes and incubated for $24 \mathrm{~h}$ to adhere. Then, cells were rinsed with PBS, fixed in $4 \%$ formalin, and permeabilized with $0.5 \%$ Triton $X-100$ in PBS for 5 min. After, washes with PBS $3 \times 5$ min, cells were blocked with $1 \%$ bovine serum albumin (BSA; Sigma-Aldrich) in PBS for $1 \mathrm{~h}$. The following antibodies were used: primary antibody monoclonal anti-PARP-6 (1:200; Santa Cruz) for overnight incubation at $4{ }^{\circ} \mathrm{C}$, and secondary antibody Fluorescein (FITC)conjugated AffiniPure Fragment Donkey Anti-Mouse IgG where the incubation for $60 \mathrm{~min}$, at RT (1:100; Jackson ImmunoResearch, Wroclaw, Poland). Cells were mounted in Fluorescence mounting medium (Sigma Aldrich) containing DNA marker - DAPI (4,6diamidino-2-phenylindole). For imaging confocal laser scanning microscope (Olympus FluoView FV1000) was used.

Statistical analysis. All values were expressed as mean \pm standard deviation (SD). Differences between groups were assessed by two- 


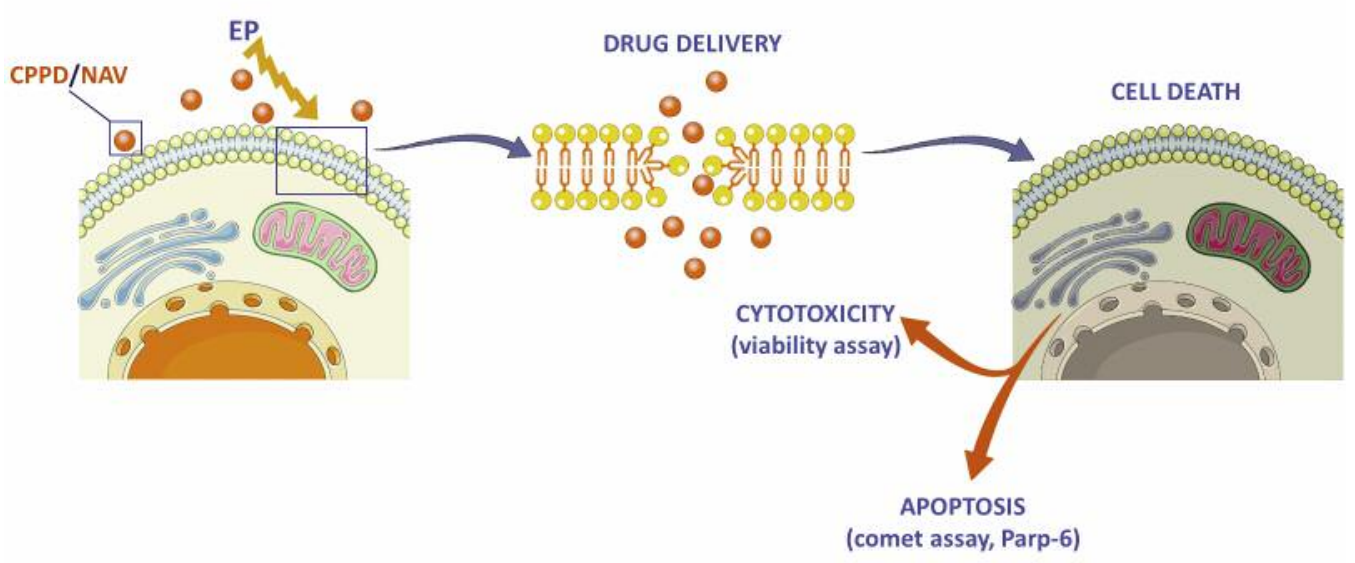

Figure 1. Schematic representation of the effect of electroporation on cancer cell membrane. Electric pulse provokes reorganization of cell membrane lipids improving drug delivery. EP, Electroporation; CPPD, cisplatin; NAV, vinorelbine.

a

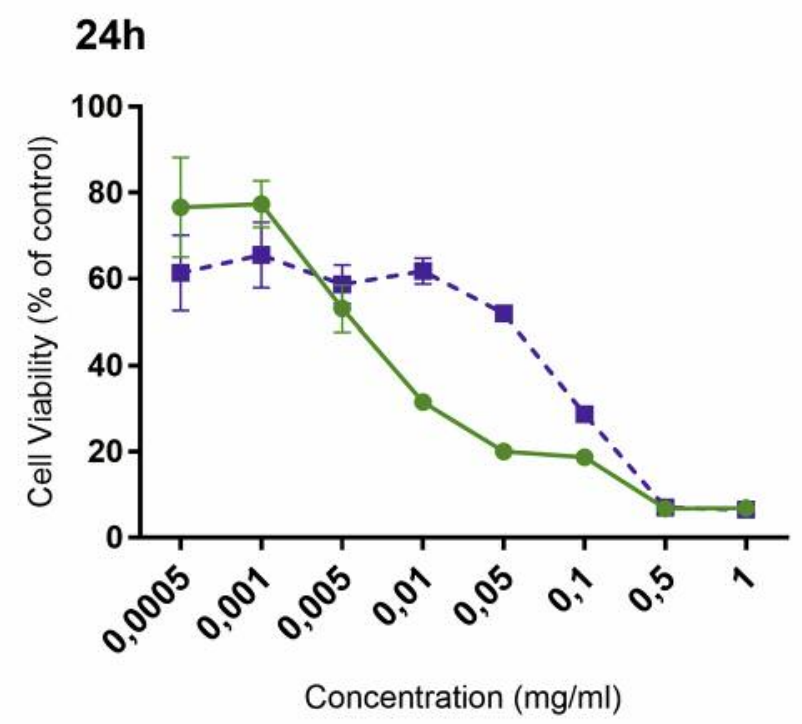

b

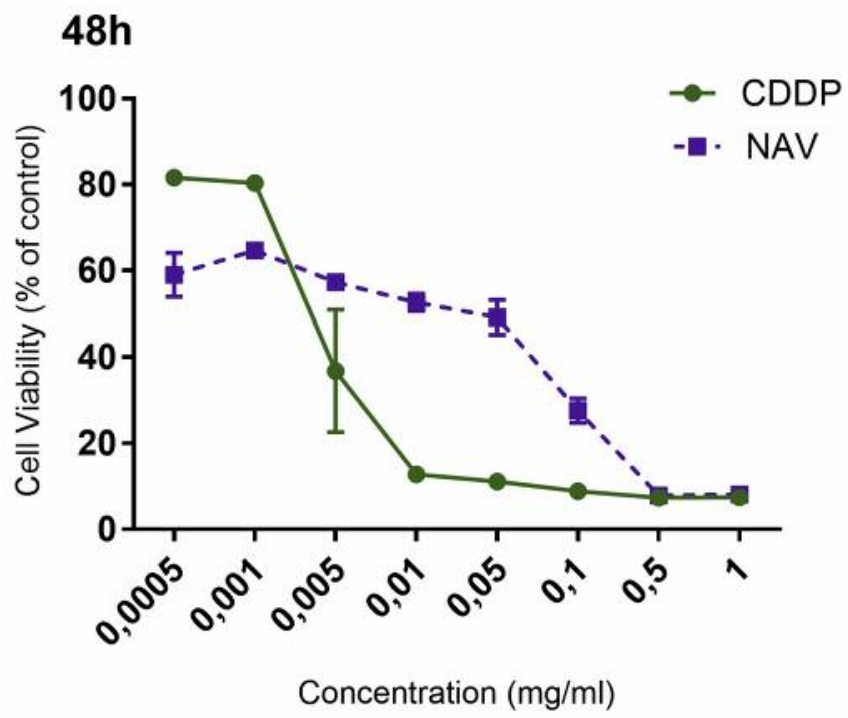

Figure 2. The cytotoxic impact of cisplatin (CDDP) and vinorelbine (NAV) on H69AR cells after $24 h(a)$ and 48 h (b) of incubation with cytostatic drugs. $S D$ for $n \geq 3$.

way analysis of variance (ANOVA). Analysis was performed using the GraphPad Prism 7 software (GraphPad Software- DMW Communication, San Diego, CA, USA). Values of $p \leq 0.05$ or $p \leq 0.01$ were considered significant.

\section{Results}

Viability studies. The cytotoxicity of the applied therapeutic modalities on H69AR cells is presented on Figure $2 \mathrm{a}$ and $\mathrm{b}$. CPPD was cytotoxic above the concentration of $0.005 \mathrm{mg} / \mathrm{ml}$, while NAV above $0.05 \mathrm{mg} / \mathrm{ml}$, at both $24 \mathrm{~h}$ and $48 \mathrm{~h}$ incubation periods (Figure 2a). Thus, H69AR cells were less sensitive to NAV than CPPD. On the other hand, there was observed a 20-25\% decrease of cell viability (MTT assay) for all the applied pulsing parameters. However, EP alone did not significantly affect the viability of lung cancer cells (Figure 3 and b). After the application of EP an increased cytotoxicity of CPPD was obtained for 1000 and 1200 electric field and $0.5 \mu \mathrm{g} / \mathrm{ml}$ (Figure 3a). The NAV was less cytotoxic than CPPD and the decreased cell viability was observed after $1200 \mathrm{~V} / \mathrm{cm}$ with $0.5 \mu \mathrm{g} / \mathrm{ml}$ NAV dose (Figure 3a). 
Apoptosis evaluation. The apoptotic cell death was detected by neutral comet assay. The obtained results were demonstrated on the Figure 4. The applied electric field induced apoptotic cell death in every selected parameter. The highest percentage of apoptotic cell was observed in 800 $\mathrm{V} / \mathrm{cm}$ (about $35 \%$ ). Also, the incubation with selected 0.5 $\mu \mathrm{g} / \mathrm{ml}$ dose of CPPD or NAV caused apoptosis in slight percent of cells (20 and 40 respectively). The combination of electroporation with standard chemotherapy expressly increased the number of apoptotic cells in every applied electric field. The highest effect was obtained for electroporation with NAV (about $80-90 \%$ of apoptotic cells) (Figure 4c).

PARP-6 evaluation. PARP-6 expression was evaluated by immunofluorescence and visualized by confocal microscope. PARP-6 positivity was detected especially in the cell cytoplasm. Higher expression of PARP-6 was noted after EP with CPPD and NAV for both selected electric field parameters, compared to control untreated cells or to cells treated with CPPD or NAV alone (Figure 5).

\section{Discussion}

SCLC very often acquires intrinsic resistance to certain anticancer drugs. Moreover, at the time of diagnosis, many patients with this type of cancer exhibit metastasis $(1,2,23$ $25)$. Thus, the occurring problem of drug resistance and metastatic spread makes reduces the effectiveness of standard therapeutic approaches, such as surgery, chemotherapy, and radiotherapy. It has been also noted that patients after chemotherapeutic protocols progressively develop genetic mutations (26-28). It may be a consequence of either activation of proto-oncogenes or inactivation of tumorsuppressor genes. These genomic instabilities can lead to tumor progression and promote metastasis, hindering treatment. Additionally, tumors that are resistant to one drug, can be either already cross-resistant or can progress resistance to other chemotherapy drugs $(29,30)$. Thus, new effective therapeutic methods are necessary for SCLC treatment.

The most frequently applied cytostatic drug is cisplatin (CPPD). Its antitumor efficacy was verified against several tumors and is currently used in clinical chemotherapy for the treatment of testicular, ovarian, head and neck, and small cell lung cancer (31). CPPD is also one of the drugs applied in electrochemotherapeutic protocols $(17,18,32-37)$. However, CPPD has still high cytotoxic impact and undesirable side effects (36-38). Therefore, new strategies to develop more potent and safe drugs are required.

In the present study, two chemotherapeutics were selected, CPPD and NAV. The increased cytotoxicity of CPPD was observed for almost all the tested drug concentrations after long incubation protocols ( 24 and 48 hours). NAV was less cytotoxic than CPPD to the examined cells. The cytotoxicity for lower concentrations was on similar level $(0.5-50 \mu \mathrm{g} / \mathrm{ml}$, respectively) and was decreasing for higher dose of vinorelbine. EP was used to improve drug penetration with the simultaneous reduction of its dose to $0.5 \mu \mathrm{g} / \mathrm{ml}$. The significant decrease of small lung cancer cells viability was noted after treatment with CPPD $0.5 \mu \mathrm{g} / \mathrm{ml}$ combined with the following EP parameters: 1000 and $1200 \mathrm{~V} / \mathrm{cm}$. Moreover, PARP-6 expression was proportionally correlated with the percentage of apoptotic cells detected by comet assay. In the previous study on pancreatic primary cell cultures derived from lung metastases, Michel et al. observed also a promising anticancer effect of EP-CPPD and an increased intensity of immunoassayed reaction of PARP-6 (38). Other authors examined the viability of sensitive SCLC cells (H69) after EP with calcium ion solution and proved that calcium EP induced significant decrease of viability for concentrations above $0.5 \mathrm{mM} \mathrm{Ca}^{2+}$ in human $\mathrm{H} 69$ cells (39). Herein, H69AR cells were applied as a drug resistant and difficult to treat lung cancer model. Our results showed that the in vitro anticancer activity of both NAV and CPPD was increased when cells were exposed to pulsed electric field. Cemazar et al. conducted similar research on CPPD-resistant human ovarian carcinoma cell lines, demonstrating that EP significantly increased the cytotoxic effect of CPPD in the cell lines IGROV-1 and IGROV-1/DDP (33).

Apoptosis avoidance in cancer is a common feature of tumor cells, and the most important reason for SCLC chemoresistance $(1,3,6,30,31)$. There are three common mechanisms through which cancer cells avoid apoptosis: (1) loss or inhibition of the p53 protein and destroying of proapoptotic proteins; (2) decreased sensitivity of the endogenous cell death machinery by altering proteins function; (3) loss of apoptosis-promoting tumor suppressor genes via accumulated mutations $(1,30,40)$. The available data indicate that in more than $80 \%$ SCLC cases the loss of wild-type of p53 activity is detected. Inhibition of the expression of cyclin-dependent kinase inhibitors p21 (WAF1) lead to abnormality of cell cycle checkpoints, and eventually generate uncontrolled cell proliferation and apoptosis blockage, which are associated with cancer progression, poor prognosis, and chemoresistance (41). In the present study, the type of cell death was detected by neutral comet assay. Additionally, immunoreactivity of PARP-6 was evaluated by immunofluorescence after ECT with CPPD and NAV. The applied electric field induced apoptotic cell death for all the used EP parameters; however, the highest percentage of apoptotic cell was observed at 800 $\mathrm{V} / \mathrm{cm}$. Also, the incubation with CPPD and NAV (without EP) caused apoptosis only in few cells. The combination of EP with standard chemotherapy expressly increased the number of apoptotic cells in each electric field intensity. The highest anticancer effect was obtained after EP combined 


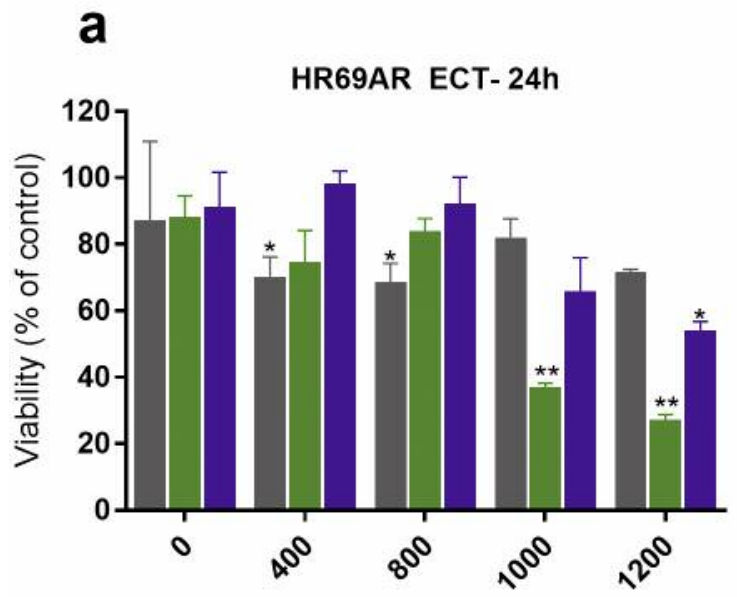

Electric field intensity $(\mathrm{V} / \mathrm{cm})$ b

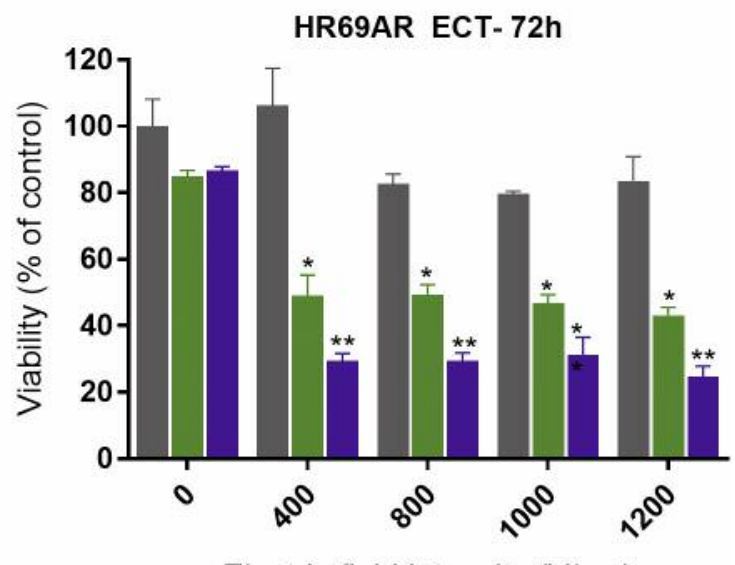

Electric field intensity $(\mathrm{V} / \mathrm{cm})$

\section{EP \\ EP+CDDP \\ - EP+NAV}

Figure 3. The cytotoxic impact of electroporation (EP) alone and electrochemotherapy $(E C T)$ with cisplatin $(C D D P)$ or vinorelbine (NAV), on H69AR cells $24 h(a)$ and $72 h(b)$ after treatment.; the duration of the incubation with cytostatic drugs was 10 min. CDDP and NAV concentration was $0.5 \mu \mathrm{g} / \mathrm{ml}$. SD for $n \geq 3 ; * p \leq 0.05$, ** $p \leq 0.01$, *** $p \leq 0.001$ (compared to untreated control).

a

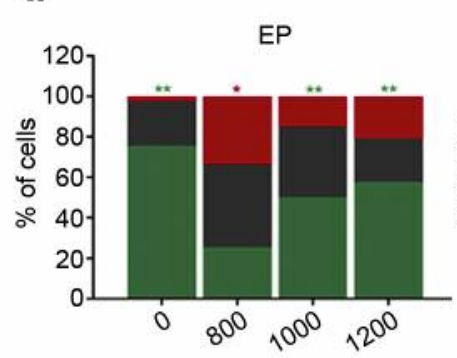

Electric field intensity $(\mathrm{V} / \mathrm{cm})$ b

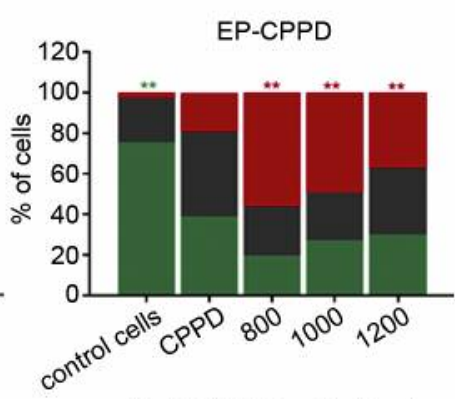

Electric field intensity $(\mathrm{V} / \mathrm{cm})$

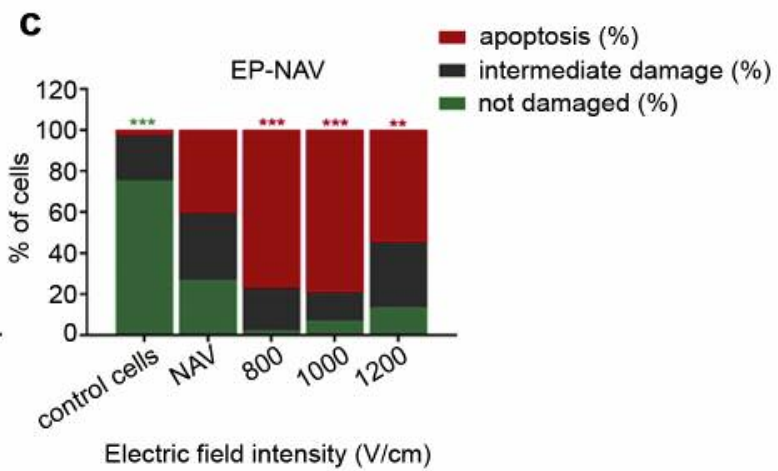

d

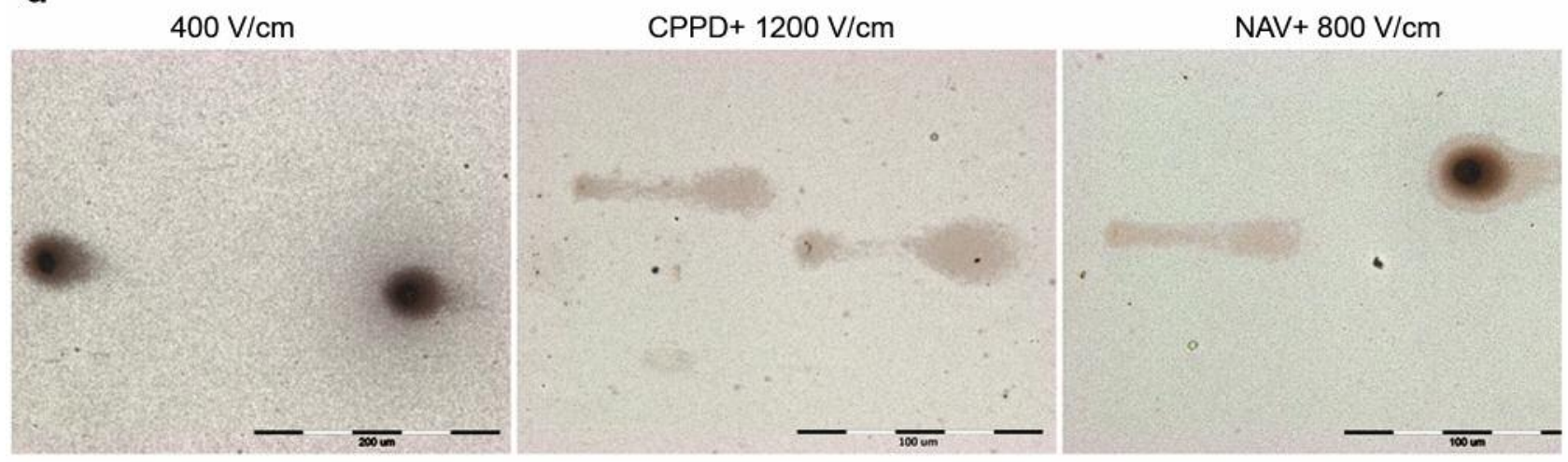

Figure 4. The neutral comet assay was performed 24 h post-treatment with electroporation (EP) (a), EP with cisplatin (CPPD) (b), and EP with vinorelbine $(N A V)(c)$. Examples of microscopic pattern of apoptotic comets are presented $(d)$; the duration of the incubation with cytostatic drugs was $10 \mathrm{~min}$. CDDP and NAV concentration was $0.5 \mu \mathrm{g} / \mathrm{ml}$. SD for $n \geq 3 ; * p \leq 0.05$, ** $\leq 0.01$ (compared to untreated control). 


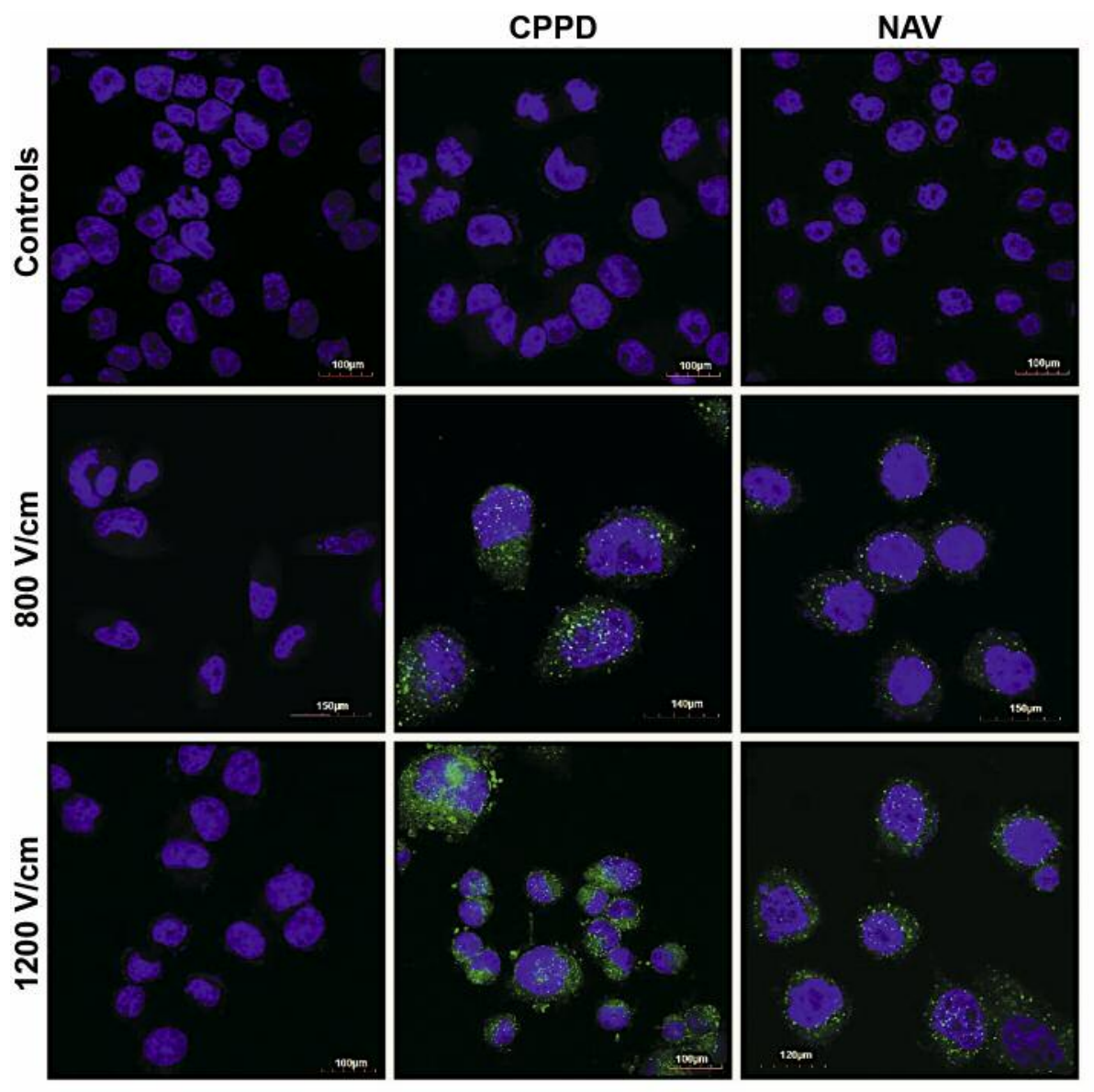

Figure 5. Immunofluorescence staining for the evaluation of PARP-6 in H69AR cells performed 24 h post-treatment with electroporation alone, and electroporation combined with cisplatin or vinorelbine. The concentration of both drugs was $0.5 \mu \mathrm{g} / \mathrm{ml}$.

with NAV. However, the significant increase of immunostained reaction of PARP-6 was observed after EP with CPPD and NAV for both selected electric fields, compared to the control untreated cells. Frandsen et al. (39) utilized calcium ions in combination with EP against small lung carcinoma. They investigated the relationship between the cell viability and intracellular ATP levels after calcium EP in several human cell lines, in vitro. The authors observed an intensified reduction of intracellular ATP level after calcium EP protocol in all treated cancer cell lines, including the SCLC cells (H69). Authors proved that cell membrane permeabilization that caused a significant decrease of ATP level $(15,39)$. The available data indicate an important role of immune response. Gardiner et al. supported that immune checkpoint inhibitor ( $\mathrm{ICH})$ therapies can be promising in preclinical and clinical trials in the treatment of non-small cell lung cancer (NSCLC). More specifically, they proposed the combination of immune therapies with local ablative techniques, such as ECT, revealing promising response rates and numerous advantages including immunostimulatory effects and overall patient comfort (40). Despite promising results, ECT seems to be technically tough to apply in lung cancers. However, advances have been achieved in this field. Kodama et al. (42) performed a trial of catheter-based endobronchial EP for the treatment of peribranchial tumors, demonstrating that this method in combination with CPPD and does not affect the patency of the treated bronchus (40). Moreover, Fanta et al. (41) used irreversible EP (IRE) for the treatment of non-small lung tumors. In order to reduce the risk of right-sided pneumonectomy, authors utilized NanoKnife device. The observation indicated the destruction of lung tumors with simultaneous protection of the lung parenchyma and pulmonary functions (43).

In conclusion, the presented here results and the available data provide information that electroporation process enables the reduction of drug doses, stimulates apoptotic cell death and immune response. Therefore, we can indicate and recommend electrochemotherapy as an alternative method that can be developed and used in small resistance lung cancer treatment, nonetheless it requires further studies. 


\section{Conflicts of Interest}

The Authors report no conflicts of interest. The authors alone are responsible for the content and writing of the paper.

\section{Authors' Contributions}

M. Drąg-Zalesińska, J. Kulbacka, J. Saczko and A. Rzechonek designed the experiments, A. Choromańska, N. Rembiałkowska and A. Szewczyk performed the experiments. J. Kulbacka and J. Saczko drafted the manuscript. M. Drąg-Zalesińska and A. Rzechonek revised the manuscript. All Authors approved the final manuscript.

\section{Acknowledgements}

The Authors would like to thank Prof. M. Kotulska from Wroclaw University of Science and Technology (Poland) for the possibility of performing electroporation tests on ECM 830 Square Wave Electroporation System (BTX, Syngen Biotech, Poland). The Authors are also very grateful to Professor P. Dzięgiel from Wroclaw Medical University for the valuable, constructive suggestions with this manuscript. The research was supported by Statutory Funds of Wroclaw Medical University No.: ST.C010.16.086 (PI: A. Rzechonek).

\section{References}

1 Chen YT, Feng B and Chen LB: Update of research on drug resistance in small cell lung cancer chemotherapy. Asian Pac J Canc Prev 13(8): 3577-3581, 2012. PMID: 23098422.

2 Rodriguez E and Lilenbaum RC: Small cell lung cancer: past, present, and future. Curr Oncol Rep 12(5): 327-334, 2010. PMID: 20632219. DOI: 10.1007/s11912-010-0120-5

3 Yu J, Wang S, Zhao W, Duan J, Wang Z, Chen H, Tian Y, Wang D, Zhao J, An T, Bai H, Wu M and Wang J: Mechanistic exploration of cancer stem cell marker voltage-dependent calcium channel $\alpha 2 \delta 1$ subunit-mediated chemotherapy resistance in small-cell lung cancer. Clin Cancer Res 24(9): 2148-2158, 2016. PMID: 29437792. DOI: 10.1158/10780432.CCR-17-1932

4 Zelen M: Keynote address on biostatistics and data retrieval. Cancer Chemother Rep 4(2): 31-42, 1973. PMID: 4580860.

5 Shepherd FA, Crowley J, Van Houtte P, Postmus PE, Carney D, Chansky K, Shaikh Z and Goldstraw P: International Association for the Study of Lung Cancer International Staging Committee and Participating Institutions: The International Association for the Study of Lung Cancer lung cancer staging project: proposals regarding the clinical staging of small cell lung cancer in the forthcoming (seventh) edition of the tumor, node, metastasis classification for lung cancer. J Thor Oncol 2(12): 1067-1077, 2007. PMID: 18090577. DOI: 10.1097/JTO.0b013e31815bdc0d

6 Mirski SE, Gerlach JH and Cole SP: Multidrug resistance in a human small cell lung cancer cell line selected in adriamycin. Canc Res 47(10): 2594-2598, 1987. PMID: 2436751.

7 DiBonaventura MD, Shah-Manek B, Higginbottom K, Penrod JR and Yuan Y: Adherence to recommended clinical guidelines in extensive disease small-cell lung cancer across the US, Europe, and Japan. Ther Clin Risk Manag 15: 355-366, 2019. DOI: $10.2147 /$ TCRM.S183216
8 Wallace AS, Arya M, Frazier SR, Westgate S, Wang Z and Doll D: Combined small-cell lung carcinoma: An institutional experience. Thor Canc 5(1): 57-62, 2014. PMID: 26766973. DOI: $10.1111 / 1759-7714.12059$

9 Moreno AC and Lin SH: The optimal treatment approaches for stage I small cell lung cancer. Transl Lung Cancer Res 8(1): 8896, 2019. DOI: $10.21037 /$ tlcr.2018.11.03

10 Guo L, Liu Y, Bai Y, Sun Y, Xiao F and Guo Y: Gene expression profiling of drug-resistant small cell lung cancer cells by combining microRNA and cDNA expression analysis. Eur J Canc 46(9): 1692-1702, 2010. PMID: 20371173. DOI: 10.1016/ j.ejca.2010.02.043

11 Napotnik TB and Miklavčič D: In vitro electroporation detection methods - An overview. Bioelectrochem 120: 166-182, 2018. PMID: 29289825. DOI: 10.1016/j.bioelechem.2017.12.005.

12 Miklavčič D, Serša G, Brecelj E, Gehl J, Soden D, Bianchi G, Ruggieri P, Rossi CR, Campana LG and Jarm T: Electrochemotherapy: technological advancements for efficient electroporation-based treatment of internal tumors. Med Biol Eng Comp 50(12): 1213-1225, 2012. PMID: 23179413. DOI: 10.1007/s11517-012-0991-8

13 Mir LM: Bases and rationale of the electrochemotherapy. Eur J Canc Supp 4(11): 38-44, 2006. DOI: 10.1016/j.ejcsup. 2006. 08.005

14 Breton M and Mir LM: Microsecond and nanosecond electric pulses in cancer treatments. Bioelectromagnet 33(2): 106-123, 2012. PMID: 21812011. DOI: 10.1002/bem.20692

15 Szewczyk A, Gehl J, Daczewska M, Saczko J, Frandsen SK and Kulbacka J: Calcium electroporation for treatment of sarcoma in preclinical studies. Oncotarget 9(14): 11604-11618, 2018. PMID: 29545923. DOI: 10.18632 /oncotarget. 24352

16 Escoffre JM and Rols MP: Electrochemotherapy: progress and prospects. Curr Pharm Des 18(23): 3406-3415, 2012. PMID: 22663554.

17 Tamzali Y, Borde L, Rols MP, Golzio M, Lyazrhi F and Teissie J: Successful treatment of equine sarcoids with cisplatin electrochemotherapy: a retrospective study of 48 cases. Equine Vet $\mathbf{J}$ 44(2): 214-220, 2012. PMID: 21793876. DOI:10.1111/ j.20423306.2011.00425.x

18 Campana LG, Testori A, Curatolo P, Quaglino P, Mocellin S, Framarini M, Borgognoni L, Ascierto PA, Mozzillo N, Guida M, Bucher S, Rotunno R, Marenco F, De Salvo GL, De Paoli A, Rossi $\mathrm{CR}$ and Bonadies A: Treatment efficacy with electrochemotherapy: A multi-institutional prospective observational study on 376 patients with superficial tumors. Eur J Sur Oncol 42(12): 19141923, 2016. PMID: 27424789. DOI: 10.1016/j.ejso.2016.06.399

19 Sadadcharam M, Soden DM and O'Sullivan CG: Electrochemotherapy: an emerging cancer treatment. Int J Hyperthermia 24(3): 263-273, 2008. DOI: 10.1080/02656730701832334

20 Tremble LF, O'Brien MA, Forde PF and Soden DM: ICOS activation in combination with electrochemotherapy generates effective anti-cancer immunological responses in murine models of primary, secondary and metastatic disease. Cancer Lett 420: 109115, 2018. PMID: 29408339. DOI: 10.1016/j.canlet.2018.01.081

21 Gehl J, Sersa G, Matthiessen LW, Muir T, Soden D, Occhini A, Quaglino P, Curatolo P, Campana LG, Kunte C, Clover AJP, Bertino G, Farricha V, Odili J, Dahlstrom K, Benazzo M and Mir LM: Updated standard operating procedures for electrochemotherapy of cutaneous tumours and skin metastases. Acta Oncol 57(7): 874-882, 2018. PMID: 29577784. DOI: 10.1080/0284186X.2018.1454602 
22 Vroomen LGPH, Petre EN, Cornelis FH, Solomon SB and Srimathveeravalli G: Irreversible electroporation and thermal ablation of tumors in the liver, lung, kidney and bone: What are the differences? Diag Interven Imag 98(9): 609-617, 2017. PMID: 28869200. DOI: 10.1016/j.diii.2017.07.007

23 Collins AR: The comet assay for DNA damage and repair: principles, applications, and limitations. Mol Biotechnol 26(3): 249-261, 2004. PMID: 15004294.

24 Qi G, Kudo Y, Tang B, Liu T, Jin S, Liu J, Zuo X, Mi S, Shao W, Ma X, Tsunematsu T, Ishimaru N, Zeng S, Tatsuka M, Shimamoto F: PARP6 acts as a tumor suppressor via downregulating Survivin expression in colorectal cancer. Oncotarget 7(14): 18812-18824, 2016. DOI: 10.18632/oncotarget.7712

25 Cole SP, Bhardwaj G, Gerlach JH, Mackie JE, Grant CE, Almquist KC, Stewart AJ, Kurz EU, Duncan AM and Deeley RG: Overexpression of a transporter gene in a multidrugresistant human lung cancer cell line. Science 258(5088): 16501654, 1992. PMID: 1360704.

26 Socinski MA, Evans T, Gettinger S, Hensing TA, VanDam Sequist L, Ireland B and Stinchcombe TE: Treatment of Stage IV non-small cell lung cancer: diagnosis and management of lung cancer, 3rd ed: American College of Chest Physicians EvidenceBased Clinical Practice Guidelines. Chest 143(5 Suppl): e341S68S, 2013. PMID: 23649446. DOI: 10.1378/chest.12-2361

27 Chan BA and Coward JIG: Chemotherapy advances in small-cell lung cancer. J Thor Dis 5(Suppl 5): S565-578, 2013. PMID: 24163749. DOI: $10.3978 /$ j.issn.2072-1439.2013.07.43

28 Schoenlein PV: Role of gene amplification in drug resistance. Cancer Treat Res 73: 167-200, 1994. PMID: 7710905.

29 Tripathi SC, Fahrmann JF, Celiktas M, Aguilar M, Marini KD, Jolly MK, Katayama H, Wang H, Murage EN, Dennison JB, Watkins DN, Levine H, Ostrin EJ, Taguchi A and Hanash SM: MCAM mediates chemoresistance in small-cell lung cancer via the PI3K/AKT/SOX2 signaling pathway. Cancer Res 77(16): 4414-4425, 2017. DOI: 10.1158/0008-5472.CAN-16-2874.

30 Kohmo S, Kijima T, Otani Y, Mori M, Minami T, Takahashi R, Nagatomo I, Takeda Y, Kida H, Goya S, Yoshida M, Kumagai T, Tachibana I, Yokota S and Kawase I: Cell surface tetraspanin CD9 mediates chemoresistance in small cell lung cancer. Canc Res 70(20): 8025-8035, 2010. PMID: 20940407. DOI: 10.1158/ 0008-5472.CAN-10-0996.

31 Nakamura M, Abe Y, Katoh Y, Oshika Y, Hatanaka H, Tsuchida T, Yamazaki H, Kijima H, Inoue H and Ueyama Y: A case of pulmonary adenocarcinoma with overexpression of multidrug resistance-associated protein and p53 aberration. Anticancer Res 20(3b): 1921-1925, 2000. PMID: 10928127.

32 Gottesman MM: Mechanisms of cancer drug resistance. Ann Rev Med 53: 615-627, 2002. PMID: 11818492.

33 Cemazar M, Sersa G and Ycld DM: Electrochemotherapy with cisplatin in the treatment of tumor cells resistant to cisplatin. Anticancer Res 18(6A): 4463-4466, 1998. PMID: 9891510.

34 Ursic K, Kos S, Kamensek U, Cemazar M, Scancar J, Bucek S, Kranjc S, Staresinic B and Sersa G: Comparable effectiveness and immunomodulatory actions of oxaliplatin and cisplatin in electrochemotherapy of murine melanoma. Bioelectrochemistry 119: 161-171, 2018. PMID: 29024870. DOI: 10.1016/j.bioelechem. 2017.09.009
35 Kranjc S, Cemazar M, Sersa G, Scancar J and Grabner S: In vitro and in vivo Evaluation of Electrochemotherapy with transplatinum Analogue trans-(PtCl2(3-Hmpy)2]. Radiol Oncol 51(3): 295-306, 2017. PMID: 28959166. DOI: 10.1515/raon-20170034.

36 Souza C, Villarino NF, Farnsworth K and Black ME: Enhanced cytotoxicity of bleomycin, cisplatin, and carboplatin on equine sarcoid cells following electroporation-mediated delivery in vitro. J Vet Pharmacol Ther 40(1): 97-100, 2017. PMID: 27287308. DOI: $10.1111 /$ jvp.12331

37 Esmekaya MA, Kayhan H, Coskun A and Canseven AG: Effects of cisplatin electrochemotherapy on human neuroblastoma cells. J Membr Biol 249(5): 601-610, 2016. PMID: 27021229.

38 Michel O, Kulbacka J, Saczko J, Mączyńska J, Błasiak P, Rossowska J and Rzechonek A: Electroporation with cisplatin against metastatic pancreatic cancer: in vitro study on human primary cell culture, BioMed Res Inter 18: 7364539, 2018. DOI: 10.1155/2018/7364539

39 Frandsen SK and Gehl J: Effect of calcium electroporation in combination with metformin in vivo and correlation between viability and intracellular ATP level after calcium electroporation in vitro. PLoS ONE 12(7): e0181839, 2017. PMID: 28742810. DOI: 10.1371 journal.pone.0181839

40 Gemba K, Ueoka H, Kiura K, Tabata M and Harada M: Immunohistochemical detection of mutant p53 protein in smallcell lung cancer: relationship to treatment outcome. Lung Cancer 29(1): 23-31, 2000. PMID: 10880844.

41 Gardiner RE, Jahangeer S, Forde P, Ariffin AB, Bird B, Soden $\mathrm{D}$ and Hinchion J: Low immunogenicity in non-small cell lung cancer; do new developments and novel treatments have a role? Cancer Metastasis Rev 34(1): 129-144, 2015. PMID: 25726003. DOI: $10.1007 / \mathrm{s} 10555-015-9550-8$

42 Kodama H, Vroomen LG, Ueshima E, Reilly J, Brandt W, Paluch L-R, Monette S, Jones D, Solomon SB and Srimathveeravalli G: Catheter-based endobronchial electroporation is feasible for the focal treatment of peribronchial tumors. J Thor Cardiovasc Sur 155(5): 2150-2159.e3, 2018. PMID: 29358001. DOI: 10.1016/ j.jtcvs.2017. 11.097

43 Fanta J, Horak P, Marvan J, Masek M, Kaspar M, Pauk N and Dvorak J: The NanoKnife and two successful cases of intracavitary irreversible electroporation of main bronchus tumours. Rozhl Chir 91(11): 625-630, 2012. PMID: 23301683.

Received February 26, 2019

Revised April 12, 2019

Accepted April 17, 2019 